\title{
Management practice, and quality of life and its associated factors among ambulatory psoriatic patients attending Dermatological Center in Addis Ababa, Ethiopia
}

\section{Seifu Megersa Kumsa}

Department of Pharmacology and Clinical Pharmacy, School of Pharmacy, College of Health Sciences, Addis Ababa University,

Tamrat Assefa Tadesse ( $\sim$ tamrat.assefa@aau.edu.et)

Department of Pharmacology and Clinical Pharmacy, School of Pharmacy, College of Health Sciences, Addis Ababa University,

Minyahil Alebachew Woldu

Department of Pharmacology and Clinical Pharmacy, School of Pharmacy, College of Health Sciences, Addis Ababa University,

\section{Research Article}

Keywords: psoriasis, Dermatology Life Quality Index, psoriasis, quality of life, Ethiopia

Posted Date: April 8th, 2021

DOI: https://doi.org/10.21203/rs.3.rs-402868/v1

License: (c) (i) This work is licensed under a Creative Commons Attribution 4.0 International License.

Read Full License 


\section{Management practice, and quality of life and its associated factors among ambulatory psoriatic patients attending Dermatological Center in Addis Ababa, Ethiopia}

Seifu Megersa Kumsa, Tamrat Assefa Tadesse, Minyahil Alebachew Woldu

Department of Pharmacology and Clinical Pharmacy, School of Pharmacy, College of Health Sciences, Addis Ababa University, Addis Ababa, Ethiopia

*Corresponding Author:

Email: tamraat.assefa@aau.edu.et

These authors contributed equally to this work. 


\begin{abstract}
Background: Psoriasis is a chronic inflammatory disease characterized by keratinocyte hyperproliferation and aberrant differentiation with great negative impact on patients' quality of life (QoL). This study aimed at assessing management practice, and quality of life (QoL) and its associated factors among ambulatory psoriatic patients visiting All Africa Leprosy, Tuberculosis and Rehabilitation Training (ALERT) Center in Addis Ababa, Ethiopia.
\end{abstract}

Materials and methods: A cross sectional study was conducted among 207 patients with psoriasis attending the dermatology clinic of ALERT Center in Addis Ababa, Ethiopia. Data were collected using structured questionnaire and patients' chart review. Dermatology Life Quality Index (DLQI) was used to measure patients' QoL. Data was analyzed entered and analyzed using Statistical Package for Social Sciences (SPSS®) version 25. Descriptive statistics like frequency, percent, mean and standard deviation were used to summarize patients' characteristics while binary logistic regression was utilized to identify predictors of quality of life.

Results: Among 207 study participants, 122(58.9\%) were females. The mean age of the study population was $37.92(\mathrm{SD}=14.86$ ) years (ranging from 16 to 68 years). The mean age at which diagnosis of psoriasis made was $32.0(\mathrm{SD}=13.7)$ years ranging from 10 to 62 years. The duration of the disease in $112(54.1 \%)$ patients were more than or equal to 5 years. Among study participants, the majority of them, 145(70.0\%) had plaque psoriasis followed by sebopsoriasis, 24(11.6\%). The majority of plaque psoriasis (80\%) cases were managed by topical corticosteroids with or without salicylic acid or coal tar and only 21(14.5\%) treated by methotrexate alone. Other forms of psoriasis were treated by only topical corticosteroids with or without salicylic acid. The mean DLQI was 6.25 corresponding to a moderate effect. Symptoms and feelings were the most affected domains of QoL. Factors associated with poor QoL were female gender $[\mathrm{AOR}=0.17$ (95\% CI: 0.06, 0.48)], low, above average and high family income ([AOR=0.12(95\% CI: 0.02, 0.56)], [AOR=0.06(95\% CI:0.01, 0.32)], and [AOR=0.03 (95\% CI: $0.01,0.22)]$ ) respectively and primary education level [AOR=0.14 (95\% CI: 0.03, 0.64)] while being on systemic therapy $[\mathrm{AOR}=4.26$ (CI: 1.18, 15.35)] was predictor of better QoL.

Conclusion: Topical corticosteroids were the mainstay of psoriasis treatment in our study. The mean DLQI was 6.25, corresponding to a moderate effect on QoL. Study participants with female gender, primary education level, and low, above average, and high monthly family 
income were considered to have worse QoL whereas receiving systemic therapy significantly associated with better QoL. Hence, future interventions targeting improving QoL and widening treatment options for psoriasis deemed to be necessary.

Keywords: psoriasis, Dermatology Life Quality Index, psoriasis, quality of life, Ethiopia 


\section{Introduction}

Psoriasis is a chronic inflammatory disease affecting skin and joints that is typically characterized by erythematous papules and plaques [1]. It is also associated with an array of significant medical and psychiatric comorbidities, including psoriatic arthritis, cardiovascular disease, diabetes, malignancy, depression, and anxiety that require timely therapy to improve long-term outcomes [2,3]. It is subject to flares and remissions that come in many different variations and degrees of severity which may be symptomatic throughout life and may be progressive with age or wax and wane in its severity [4].

Based on morphologic characteristics, several subtypes of psoriasis have been identified which is necessary to guide appropriate management. However, clinical findings often fit into more than one category. The most common subtypes are plaque, guttate, erythrodermic, pustular, and inverse psoriasis [5,6]. Psoriasis is a worldwide disease, despite its prevalence varies among different ethnicities and geographic locations, affecting about $2 \%-3 \%$ of the world's population [7]. Higher altitudes are associated with the largest prevalence. Northern Europe appears to be one of the highest whereas East Asia tends to have the lowest rates. Similarly, global reports on psoriasis showed that prevalence varies from $0.09 \%$ to $11.4 \%[7,8]$.

The treatment of psoriasis comprises topical agents, phototherapy, systemic immunosuppressants, and, more recently, biologics [9]. Topical agents are widely used for localized and milder forms of these diseases and to control flares of skin disease in patients with widespread or more severe one while systemic therapies are reserved for more severe disease as long term use has significant side effects, despite a number of immunobiologics introduced recently has high efficacy with reduced side-effect potential [10].

Psoriasis has a negative impact on the psychological status, social interaction, and overall quality of life $(\mathrm{QoL})$ of the patients [11,1]. Various studies showed that psoriasis affects day-to-day activities, occupational, and sexual functioning, often independent of the extent, and severity of skin lesions [12-15]. It was also demonstrated that it can cause anxiety, depression, anger, and embarrassment, which then leads to social isolation and absenteeism at work and school. Social and sporting activities can become difficult since they worry about what other people think of their appearance (14). It has also great economic and financial consequences [15]. 
There are unmet needs regarding the management of psoriasis in Africa [16]. Also, there is no generally accepted consensus definition to say the treatment is successful or not, so that patient care should include the provision of effective, convenient, and safe drugs, patient-reported outcomes like treatment preference, satisfaction, and QoL [17]. In Ethiopia, little is known about the level of quality of life and its determinants in psoriatic patients. Therefore, this study seeks to evaluate management practice, quality of life, and its associated factors among ambulatory psoriatic patients attending ALERT Hospital.

\section{Materials and methods}

\section{Study setting}

The study was conducted in the dermatology clinic of All Africa Leprosy, Tuberculosis and Rehabilitation Training Center (ALERT), located in Addis Ababa, Ethiopia which was established by the Sudan Interior Mission in 1934. ALERT Center is one of the leading specialized hospitals in dermatology, ophthalmology, and plastic and reconstructive surgery in the country.

\section{Study design and period}

Hospital-based cross-sectional study design that involved interviewing patients and reviewing their charts retrospectively was used in this study. Patients' interview was conducted from 1st July to December 31, 2019, while data extraction period was from December 31, 2018 to December 31, 2019 for the same patients.

\section{Eligibility criteria}

All patients with psoriasis and visiting dermatologic clinic during the study period and patients with age $\geq 16$ years, who were on active follow-up and receiving treatment for at least 6 months were included in our study. Whereas being physically ill, having $\geq 2$ questions not answered in DLQI questionnaires, and unable to speak Amharic or didn't have a caregiver to facilitate communication in case of difficulty, patients having incomplete medical records were excluded from this study. 


\section{Sample size and sampling technique}

The sample size was computed based on a single population proportion formula. Since there was no previous study conducted on the QOL among psoriasis in Ethiopia, the proportion was taken as $50 \%$ and accordingly sample size was calculated to be 384 . However, during the study period (1st July to December 31, 2019), 504 patients $(<10,000)$ visited the clinic i.e. about 21 patients; the finite population correction formula is used to calculate the actual sample size which was 218. Taking a $10 \%$ contingency (non-response rate), the final sample became 240 in our study. A systematic random sampling method was used to recruit samples for the study on each day of the data collection process. Sampling interval $(\mathrm{kth})$ was determined by dividing the total number of psoriatic patients that came within the study period (six months) by estimated sample size (kth $=504 / 240=2$ ), thus, the first patient was selected randomly then every other patient was interviewed following physicians visit until the required sample was reached. In this study, 207 study participants were included in the final analysis after excluding patients with incomplete data.

\section{Study variables}

QOL and management practice were considered as dependent variables while age, sex, educational status, marital status, occupation, monthly income, social drug habits, comorbidity, type of psoriasis, treatment modality, duration of psoriasis treatment, type and number of drugs were independent variables affecting QOL in this study.

\section{Data collection tool}

Data were collected using a structured data abstraction tool through interviewing patients and reviewing their medical records. The first part of the tool comprised socio-demographic character (age, sex, educational status, monthly income, occupation, alcohol intake, chat chewing, and smoking status). The second part was the DLQI questionnaire which was used to measure QoL. The final section comprised a tool to collect relevant clinical data like types of psoriasis, age at initial diagnosis, duration of disease, current medications, and comorbidities. The first part was translated into Amharic language and the Amharic version was administered to study participants. 
The DLQI questionnaire was the first dermatology-specific quality of life questionnaire. It consists of questions concerning patients' perception of the impact of skin diseases on different aspects of their health-related quality of life over the last week. It was widely used in clinical studies of more than 80 countries and translated into more than 110 languages including Amharic [18]. DLQI is a 10-item questionnaire were questions 1 and 2 assess symptoms and feelings; 3 and 4, daily activities; 5 and 6, leisure; 7, work or school; 8 and 9, personal relationships; and 10, treatment. The DLQI was rated on a 4-point scale with corresponding values of $3=$ very much, 2 $=\mathrm{a}$ lot, $1=\mathrm{a}$ little and $0=$ not at all; $0=$ not relevant for each item. The highest sum is 30, and the lowest 0 , and interpretation is: 0 to 1 score $=$ no effect; 2 to $5=$ small effect; 6 to $10=$ moderate effect; 11 to $20=$ large effect and 21 to $30=$ extremely serious effect on patient's life.

\section{Data collectors and quality assurance}

Data were collected by two nurses working in the outpatient dermatologic clinic under the supervision of the principal investigator. The principal investigator gave one-day training for data collectors on the study's purpose, how to conduct a patient interview, and collect data from the patients' charts. A pretest was done on twenty patients before actual data collection to check uniformity and understandability of the data collection tool and necessary modifications were made to the data collection tool. The pre-tested patients were excluded from the analysis. The principal investigator closely supervised the data collection process and was giving feedback and correction daily to maintain the quality of data.

\section{Data analysis}

After cleaning incomplete data, collected data was entered and analyzed using Statistical Package for Social Sciences (SPSS) version 25. Descriptive statistics were used for analyses of socio-demographic variables and relevant clinical data. Categorical variables were described by frequencies and percentages, and continuous variables were expressed by means and standard deviations. Binary logistic regression analysis was used to identify the determinants of QoL. Variables with $\mathrm{P}<0.25$ in univariate analysis were further analyzed by multiple logistic regressions to avoid confounders. A p-value $<0.05$ was used to confirm an association. 


\section{Ethical considerations}

Ethical approval was received from the Ethical Review Board of the School of Pharmacy, College of Health Sciences, Addis Ababa University (Ref No: ERB/SOP/103/06/2019), and then permission was also obtained from ALERT Hospital, Department of Dermatology. In addition, informed written consent was obtained from the study participants and confidentiality was maintained by omitting patient identifiers and giving code number.

\section{Results}

\section{Demographic characteristics of patients}

A total number of 207 participants were included for the final analysis. One hundred twenty-two (58.9\%) were females. The mean age of the study population was $37.92(\mathrm{SD}=14.86)$ years (ranging from 16 to 68 years) (Table 1).

Table 1: Socio-demographic characteristics of psoriasis patients attending Dermatology Clinic of ALERT Center, Addis Ababa, Ethiopia (N=207).

\begin{tabular}{|l|l|l|}
\hline Socio-demographic & Category & Number (\%) \\
\hline \multirow{4}{*}{ Sex } & Male & $85(41.1)$ \\
\cline { 2 - 3 } & Female & $122(58.9)$ \\
\hline \multirow{5}{*}{ Marital status } & $16-35$ & $106(51.2)$ \\
\cline { 2 - 3 } & $36-60$ & $75(36.2)$ \\
\cline { 2 - 3 } & $>60$ & $26(12.6)$ \\
\hline \multirow{5}{*}{ Educational status } & Single & $61(29.5)$ \\
\cline { 2 - 3 } & Married & $124(59.9)$ \\
\cline { 2 - 3 } & Divorced & $6(2.9)$ \\
\cline { 2 - 3 } & Widowed & $39(7.7)$ \\
\hline & Unable to read and write & $46(22.2)$ \\
\cline { 2 - 3 } & Primary school (Grade 1-8) & $74(21.3)$ \\
\cline { 2 - 3 } & Secondary school (Grade 9-12) & $78(37.7)$ \\
\cline { 2 - 3 } & Higher education (Diploma \\
\hline
\end{tabular}




\begin{tabular}{|c|c|c|}
\hline & and above) & \\
\hline \multirow[t]{8}{*}{ Occupation } & Farmer & $24(11.6)$ \\
\hline & Merchant/self-employed & $46(22.2)$ \\
\hline & Employee & $53(25.6)$ \\
\hline & Unemployed & $14(6.8)$ \\
\hline & Housewife & $22(10.6)$ \\
\hline & Student & $29(14.0)$ \\
\hline & Daily laborer & $10(4.8)$ \\
\hline & Others* & $9(4.3)$ \\
\hline \multirow{5}{*}{$\begin{array}{l}\text { Monthly family income } \\
(\mathrm{ETB}) * *\end{array}$} & Very low $(\leq 860)$ & $32(15.5)$ \\
\hline & Low (861-1500) & $42(20.3)$ \\
\hline & Average (1501-3000) & $24(11.6)$ \\
\hline & Above average (3001-5000) & $32(15.5)$ \\
\hline & High $(\geq 5001)$ & $77(37.2)$ \\
\hline \multirow[t]{3}{*}{ Social drug habits } & Active cigarette smoker & $3(1.4)$ \\
\hline & Regular alcohol user & $7(3.4)$ \\
\hline & Regular chat chewer & $11(5.3)$ \\
\hline
\end{tabular}

ETB- Ethiopian birr; *retired, broker, guard, ** based on Ethiopian civil service monthly salary scale for civil servants

In this study, 124 (59.9\%) were married participants and 78 (37.7\%) participants were educated up to diploma and above. Of the total patients, 53(25.6\%) were employees followed by merchant/self-employed 46(22.2\%), and 77(37.2\%) patients had a high level of monthly family income.

\section{Clinical characteristics of patients}

As shown in Table 2, the mean age at which the diagnosis of psoriasis made was 32.0 [(standard deviation $(\mathrm{SD})=13.7]$ years. The duration of the disease in $112(54.1 \%)$ patients were more than or equal to 5 years. 
Table 2: Clinical characteristics of psoriasis patient attending dermatology clinic of ALERT Center, Addis Ababa, Ethiopia ( $N=207)$.

\begin{tabular}{|c|c|c|c|c|}
\hline Factors & Category & $\mathrm{N}(\%)$ & Mean \pm SD & Range \\
\hline \multirow[t]{3}{*}{ BMI $\left(\mathrm{Kg} / \mathrm{m}^{2}\right)$} & $\leq 18.5$ & $15(7.2)$ & & \\
\hline & $18.5-24.9$ & $158(76.3)$ & & \\
\hline & $25.0-29.9$ & $17(8.2)$ & & \\
\hline \multirow{2}{*}{$\begin{array}{l}\text { Age at initial } \\
\text { diagnosis (in years) }\end{array}$} & Early onset $(<40)$ & $144(69.6)$ & \multirow[t]{2}{*}{$32.0 \pm 13.7$} & \multirow[t]{2}{*}{$10.0-62.0$} \\
\hline & Late-onset $(\geq 40)$ & 63(30.4) & & \\
\hline \multirow{2}{*}{$\begin{array}{l}\text { Duration of the } \\
\text { disease (in years) }\end{array}$} & $<5$ & 95 (45.9) & \multirow[t]{2}{*}{$5.6 \pm 3.6$} & \multirow[t]{2}{*}{$0.8-18.7$} \\
\hline & $\geq 5$ & $112(54.1)$ & & \\
\hline \multirow[t]{6}{*}{ Types of psoriasis } & Plaque psoriasis & $145(70.0)$ & & \\
\hline & Sebopsoriasis & 24 (11.6) & & \\
\hline & Scalp psoriasis & $22(10.6)$ & & \\
\hline & Palmoplantar psoriasis & $13(6.3)$ & & \\
\hline & Pustular psoriasis & $2(1.0)$ & & \\
\hline & Inverse and nail psoriasis & $1(0.5)$ & & \\
\hline \multirow[t]{2}{*}{ Comorbid diseases } & Yes & $6(2.9)$ & & \\
\hline & No & $201(97.1)$ & & \\
\hline \multirow{3}{*}{$\begin{array}{l}\text { Specific comorbidity } \\
\text { presented }\end{array}$} & HIV & $3(1.4)$ & & \\
\hline & Hypertension & $2(1.0)$ & & \\
\hline & $\begin{array}{l}\text { Diabetes mellitus and } \\
\text { hypertension }\end{array}$ & $1(0.5)$ & & \\
\hline \multirow[t]{3}{*}{ Treatment modality } & Topical corticosteroids & $174(84.1)$ & & \\
\hline & Systemic agent & $22(10.6)$ & & \\
\hline & $\begin{array}{l}\text { Topical corticosteroids } \\
\text { and systemic agents }\end{array}$ & $11(5.3)$ & & \\
\hline
\end{tabular}

The majority of study populatition, $145(70.0 \%)$ had plaque psoriasis followed by sebopsoriasis $24(11.6 \%)$. In the present study, $158(76.3 \%)$ patients were in the normal body mass index 
(BMI) range and only $6(2.9 \%)$ patients had comorbid diseases among which human immunodeficiency virus (HIV) and hypertension accounted for $1.4 \%$ and $1.0 \%$ respectively.

\section{Anti-psoriatic drug utilization practice}

In our study, $185(89.4 \%)$ of patients received topical corticosteroids for the treatment of psoriasis, and $12(6.5 \%)$ patients have prescribed two topical steroids with different potency. Methotrexate was found to be prescribed for 33(15.9\%) patients. The average number of antipsoriatic drugs prescribed per patient was $1.8(\mathrm{SD}=0.7)$. Regarding the management of specific types of psoriasis, plaque psoriasis was mostly managed by topical therapy alone, topical corticosteroids with or without salicylic acid/coal tar, $113(77.9 \%)$ but only 21(14.5\%) treated by methotrexate alone. All patients with palmoplantar, sebopsoriasis, scalp, and pustular psoriasis were treated only by topical corticosteroids with or without salicylic acid.

Table 3: Anti-psoriatic drugs utilization pattern among psoriasis patients attending ALERT Center, Addis Ababa, Ethiopia (N=207).

\begin{tabular}{|c|c|c|c|c|c|c|c|}
\hline \multirow[t]{2}{*}{ Treatments } & \multicolumn{6}{|c|}{ Types of Psoriasis, N (\%) } & \multirow{2}{*}{$\begin{array}{l}\text { Total } \\
\text { N }(\%)\end{array}$} \\
\hline & $\begin{array}{l}\text { Plaque } \\
\mathrm{N}=145\end{array}$ & $\begin{array}{l}\text { Inverse } \\
\text { and nail } \\
\mathrm{N}=1\end{array}$ & $\begin{array}{l}\text { Palmoplan } \\
\text { tar } \\
\mathrm{N}=11\end{array}$ & $\begin{array}{l}\text { Sebopsor } \\
\text { iasis } \\
\mathrm{N}=26\end{array}$ & $\begin{array}{l}\text { Scalp } \\
\mathrm{N}=22\end{array}$ & $\begin{array}{l}\text { Pustular } \\
\mathrm{N}=2\end{array}$ & \\
\hline \multicolumn{7}{|c|}{ Topical corticosteroids } & $185(89.4)$ \\
\hline $\begin{array}{l}\text { Betamethasone } \\
\text { dipropoinate }\end{array}$ & $106(73.1)$ & $0(0)$ & $2(18.2)$ & $22(84.6)$ & $20(90.9)$ & $2(100)$ & $150(81.1)$ \\
\hline $\begin{array}{l}\text { Clobetasone } \\
\text { propionate }\end{array}$ & $5(3.4)$ & $0(0)$ & $6(54.5)$ & $0(0)$ & $0(0)$ & $0(0)$ & $12(6.5)$ \\
\hline $\begin{array}{l}\text { Mometasone } \\
\text { furoate }\end{array}$ & $11(7.6)$ & $0(0)$ & $2(18.2)$ & $4(16.7)$ & $0(0)$ & $0(0)$ & $17(9.2)$ \\
\hline $\begin{array}{l}\text { Clocortolone } \\
\text { pivolate }\end{array}$ & $8(5.5)$ & $0(0)$ & $3(27.3)$ & $0(0)$ & $2(9.1)$ & $0(0)$ & $12(6.5)$ \\
\hline \multicolumn{7}{|c|}{ Other topical agents } & \\
\hline Salicylic acid & $86(59.3)$ & $0(0)$ & $7(63.6)$ & $16(66.7)$ & $6(27.3)$ & $0(0)$ & $115(55.6)$ \\
\hline Coal tar & $8(5.5)$ & $0(0)$ & $0(0)$ & $0(0)$ & $0(0)$ & $0(0)$ & $8(3.9)$ \\
\hline
\end{tabular}




\begin{tabular}{|l|c|c|c|c|c|c|c|}
\hline Systemic agents (traditional) \\
\hline Methotrexate & $32(22.1)$ & $1(100)$ & $0(0)$ & $0(0)$ & $0(0)$ & $0(0)$ & $33(16.0)$ \\
\hline \multicolumn{7}{|c|}{ Mean \pm SD } \\
\hline $\begin{array}{l}\text { No. of drugs } \\
\begin{array}{l}\text { No. of } \\
\text { preparation }\end{array}\end{array}$ & $1.8 \pm 0.7$ & $1.0 \pm 0.0$ & $2.0 \pm 0.7$ & $2.5 \pm 0.7$ & $1.4 \pm 0.5$ & $1.0 \pm 0.0$ & $1.8 \pm 0.7$ \\
\hline
\end{tabular}

\section{Quality of Life Domains}

According to DLQI, 104 (50.2\%) patients experienced a small effect and only 4(2.0\%) patients had an extremely large effect on the quality of life (Fig 1).

Figure 1: Proportion of overall effect of psoriatic on quality of life among psoriasis patients attending ALERT Hospital, Addis Ababa, Ethiopia ( $N=207)$.

Among DLQI domains, symptom and feeling was the highest affected domain, with a total value of 541 , followed by treatment, with a total value of 287 , followed by daily activities, with a total value of 232 and the least affected domain was work and school, with a total value of 54 (Table 4). The mean DLQI was 6.25 corresponding to a moderate effect and symptoms and feeling were the most affected domains of QoL.

\section{Factors associated with quality of life}

Based on the results of univariate binary logistic regression analysis, variables such as gender, age group, educational status, occupation, family income, regular use of alcohol, BMI, age at initial diagnosis, and treatment modality were included in the multivariate binary logistic regression analysis, and accordingly, gender, educational status, family income, and treatment modality had a significant association with quality of life. The odds of having better QoL (DLQI $\leq 5)$ for female patients was decreased by 83\% [AOR=0.17 (95\% CI: 0.06, 0.48)], $(\mathrm{P}=0.001)$. This study also found a statistically significant association between primary educational status and poor quality of life $[\mathrm{AOR}=0.14$ (95\% CI: 0.03, 0.64)] ( $\mathrm{P}=0.011)$. The odds of having better QoL (DLQI $\leq 5)$ were more than four times higher among patients on systemic therapy as compared to those on topical only $[\mathrm{AOR}=4.26$ (CI:1.18,15.35)] $(\mathrm{P}=0.027)$ (Table 5). 
Table 4: Quality of life domains of psoriatic patients attending Dermatologic Clinic of ALERT Hospital, Addis Ababa, Ethiopia (N=207).

\begin{tabular}{|l|c|c|c|c|c|}
\hline Domains & $\begin{array}{l}\text { Question } \\
\text { Number }\end{array}$ & Mean & $\begin{array}{l}\text { Minimum } \\
\text { value }\end{array}$ & $\begin{array}{l}\text { Maximum } \\
\text { value }\end{array}$ & Total value \\
\hline Symptoms and & 1 & 1.84 & 0 & 3 & 380 \\
\cline { 2 - 6 } feelings & 2 & 0.78 & 0 & 3 & 161 \\
\hline Daily activities & 3 & 0.22 & 0 & 3 & 45 \\
\cline { 2 - 6 } & 4 & 0.90 & 0 & 3 & 187 \\
\hline Leisure & 5 & 0.23 & 0 & 3 & 47 \\
\hline Work and School & 7 & 0.22 & 0 & 3 & 46 \\
\cline { 2 - 6 } & & 0.25 & 0 & 3 & 51 \\
\hline Personal & 0.02 & 0 & 1 & 3 \\
\hline relationships & 9 & 0.31 & 0 & 3 & 284 \\
\hline Treatment & 10 & 1.39 & 0 & 3 & 1294 \\
\hline Overall DLQI & & 6.25 & 0 & 29 & 3 \\
\hline
\end{tabular}

Table 5: Logistic regression analysis of factors associated with QoL among psoriasis patients attending Dermatologic Clinic of ALERT Hospital, Addis Ababa, Ethiopia (N=207).

\begin{tabular}{|l|l|l|l|l|l|}
\hline \multirow{2}{*}{ Variables } & \multicolumn{2}{|c|}{ DLQI, $\mathbf{n}(\%)$} & \multicolumn{2}{l|}{ OR (95\% CI) } & $\begin{array}{l}\text { P- } \\
\text { value }\end{array}$ \\
\cline { 2 - 6 } & $\mathbf{5}$ & $>\mathbf{5}$ & Crude & Adjusted & \\
\hline Sex & $35(41.18)$ & $50(58.82)$ & 1.00 & 1.00 & \\
\hline Male & $82(67.21)$ & $40(32.79)$ & $0.34(0.19,0.61)$ & $0.17(0.06,0.48)$ & $0.001^{*}$ \\
\hline Female & \multicolumn{7}{|l|}{} & \\
\hline Age group & $66(62.26)$ & $40(37.74)$ & 1.00 & 1.00 & 0.872 \\
\hline $36-35$ & $44(58.67)$ & $31(41.33)$ & $1.16(0.64,2.13)$ & $0.92(0.33,2.60)$ & 0.109 \\
\hline$>65$ & $7(26.92)$ & $19(73.08)$ & $4.48(1.73,11.60)$ & $5.50(0.68,44.27)$ & \\
\hline
\end{tabular}




\begin{tabular}{|c|c|c|c|c|c|}
\hline \multicolumn{6}{|c|}{ Educational status } \\
\hline $\begin{array}{l}\text { Can't read and } \\
\text { write }\end{array}$ & $18(46.15)$ & $21(53.85)$ & 1.00 & 1.00 & \\
\hline Primary & $38(82.61)$ & $8(17.39)$ & $0.18(0.07,0.49)$ & $0.14(0.03,0.64)$ & $0.011 *$ \\
\hline Secondary & $22(50)$ & $22(50)$ & $0.86(0.36,2.03)$ & $3.26(0.65,16.50)$ & 0.152 \\
\hline Higher & $39(50)$ & $39(50)$ & $0.86(0.40,1.85)$ & $4.18(0.75,23.62)$ & 0.102 \\
\hline \multicolumn{6}{|l|}{ Occupation } \\
\hline Farmer & $11(45.83)$ & $13(54.17)$ & 1.00 & 1.00 & \\
\hline Merchant & $33(71.74)$ & $13(28.26)$ & $0.33(0.12,0.93)$ & $0.87(0.16,4.56)$ & 0.865 \\
\hline Employee & $27(50.94)$ & $26(49.06)$ & $0.82(0.31,2.14)$ & $1.28(0.23,7.07)$ & 0.774 \\
\hline Unemployed & $5(35.71)$ & $9(64.29)$ & $1.52(0.39,5.91)$ & $1.89(0.22,16.00)$ & 0.560 \\
\hline House wife & $14(63.64)$ & $8(36.36)$ & $0.48(0.15,1.58)$ & $4.80(0.78,29.60)$ & 0.091 \\
\hline Student & $21(72.41)$ & $8(27.59)$ & $0.32(0.10,1.01)$ & $2.32(0.26,20.80)$ & 0.450 \\
\hline Daily laborer & $4(40)$ & $6(60)$ & $1.27(0.28,5.68)$ & $5.48(0.56,53.95)$ & 0.145 \\
\hline Others & $2(22.22)$ & $7(77.78)$ & $2.96(0.51,17.30)$ & $0.94(0.04,20.11)$ & 0.970 \\
\hline \multicolumn{6}{|c|}{ Monthly family income (ETB) } \\
\hline Very low $\leq 860$ ) & $10(31.25)$ & $22(68.75)$ & 1.00 & 1.00 & \\
\hline Low (861-1500) & $32(76.19)$ & $10(23.81)$ & $0.14(0.05,0.40)$ & $0.12(0.02,0.56)$ & $0.007 *$ \\
\hline $\begin{array}{l}\text { Average (1501- } \\
3000)\end{array}$ & $8(33.33)$ & $16(67.67)$ & $0.91(0.29,2.82)$ & $0.24(0.04,1.43)$ & 0.117 \\
\hline $\begin{array}{l}\text { Above average } \\
(3001-5000)\end{array}$ & $19(59.38)$ & $13(40.62)$ & $0.31(0.11,0.87)$ & $0.06(0.01,0.32)$ & $0.001 *$ \\
\hline $\operatorname{High}(\geq 5001)$ & $48(62.34)$ & $29(37.66)$ & $0.28(0.11,0.66)$ & $0.03(0.01,0.22)$ & $<0.001 *$ \\
\hline \multicolumn{6}{|c|}{ Regular use of alcohol } \\
\hline No & 115(57.79) & $84(42.21)$ & 1.00 & 1.00 & \\
\hline Yes & $2(25)$ & $6(75)$ & $4.11(0.81,20.85)$ & $8.05(0.55,117.65)$ & 0.128 \\
\hline \multicolumn{6}{|l|}{ BMI } \\
\hline Underweight & $3(20)$ & $12(80)$ & 1.00 & 1.00 & \\
\hline Normal & $93(58.86)$ & $65(41.14)$ & $0.18(0.05,0.64)$ & $0.28(0.06,1.36)$ & 0.114 \\
\hline Overweight & $7(41.18)$ & $10(58.82)$ & $0.36(0.07,1.75)$ & $0.86(0.10,7.31)$ & 0.889 \\
\hline
\end{tabular}




\begin{tabular}{|l|l|l|l|l|l|}
\hline \multicolumn{6}{|l|}{ Age at initial diagnosis (in years) } \\
\hline$<40$ & $90(62.5)$ & $54(37.5)$ & 1.00 & 1.00 & \\
\hline$\geq 40$ & $27(42.86)$ & $36(57.14)$ & $2.22(1.22,4.06)$ & $1.82(0.47,7.04)$ & 0.384 \\
\hline Treatment modality & $104(59.43)$ & $71(40.57)$ & 1.00 & 1.00 & \\
\hline Topical & $7(33.33)$ & $14(67.67)$ & $2.93(1.13,7.62)$ & $4.26(1.18,15.35)$ & $0.027^{*}$ \\
\hline Systemic & $6(54.54)$ & $5(45.46)$ & $1.22(0.36,4.15)$ & $0.73(0.10,5.61)$ & 0.765 \\
\hline $\begin{array}{l}\text { Topical and } \\
\text { systemic }\end{array}$ & & & & \\
\hline
\end{tabular}

*- statistically significant at $\mathrm{P}<0.05$

\section{Discussion}

In this study, different medication regimens were used in the management of psoriasis. Topical corticosteroids were the most commonly prescribed medication, followed by methotrexate, in treating plaque psoriasis. Topical corticosteroids having anti-inflammatory, antiproliferative, immunosuppressive, and vasoconstrictive effects hence considered as a cornerstone of treatment in those patients with the limited disease [19]. Similarly, methotrexate is folate synthesis inhibitor, used for the treatment of psoriasis due to its cytostatic and anti-inflammatory properties [3]. Likewise, different guidelines regarding the treatment of psoriasis vulgaris have shown that topical corticosteroids and methotrexate are one of the first lines for treating mild and moderatesevere psoriasis respectively [20-24]. Corticosteroids can even be used as an adjunct to systemic therapy or phototherapy for moderate-to-severe psoriasis [5,24]. Among patients with plaque psoriasis, extemporaneous preparation of salicylic acid with topical corticosteroids was prescribed for $86(59.3 \%)$ patients. This could be due to the fact that salicylic acid, a keratolytic agent by itself, enhances steroid efficacy by increasing penetration [3,21]. Palmoplantar psoriasis, sebopsoriasis and scalp psoriasis were managed by topical corticosteroids alone or in combination with salicylic acid. This is in agreement with different clinical guidelines [22, 23].

Regarding the management of pustular psoriasis, the present study revealed that topical corticosteroids were the most commonly used treatment regimen. Contrastingly, clinical guideline done by National Psoriasis Foundation [22] did not state topical corticosteroids among both first and second-line therapy for treating such patients but rather recommended biologics. 
The probable reasons can be unavailability of biologics and lack of local standard treatment guidelines for the management of psoriasis in the studied hospital. Extemporaneous preparation containing coal tar with topical corticosteroids was prescribed for 8(3.9\%) patients. Guideline on the management of psoriasis in South Africa showed that coal tar is recommended in patients with mild psoriasis who require an inexpensive alternative to corticosteroids [21]. Various guidelines also exposed that coal tar can be used for treating localized psoriasis, but it has poor tolerability by patients due to its irritation property, cosmetic issues like odor, and staining of clothes [5, 19,23]. So, patients prescribed for coal tar need higher attention.

In the present study, the mean DLQI was found to be 6.25 , corresponding to a moderate effect of psoriasis on patients' QoL. The result was somewhat similar to a hospital-based cross-sectional study done in India [24], Malaysia [25], and Russia [26], which reported 8.10, 8.5, and 7.1 respectively. However, Egyptian study found a higher mean DLQL (12.2\%), corresponding to a very large effect [27]. The first reason for this variation could be our study included all types of psoriasis, unlike the study done in Egypt which incorporated only psoriasis of chronic plaquetype and the second reason might be the difference in the severity of the disease among study participants as far as this study was carried out among outpatients only.

In the present study, only 13 (6.3\%) patients replied that the disease has no effect on their quality of life which is similar to a report of Indian study, 6.1\% (24). Among DLQI domains symptoms and feelings were the highly affected domain. The present result is in line with studies done in India [24,28], Taiwan [29], and Egypt [27]. This is due to the fact that the domain encompasses questions directed to identify the level of embarrassment and painfulness or itchiness owing to the disease which is used to even define the disease in the case of global reports on psoriasis [8].

The identification of risk factors for a marked reduction in quality of life owing to psoriasis is important as it helps to identify the most susceptible patient who requires close monitoring. The result of this study showed female gender was found to be independent predictors, which increases the chance of having poor quality of life. This was supported by a similar study done in India [30], the United States of America [31], Spain [32]. The probable reason could be the fact that females are more concerned about their body image and physical appearance than their male counterparts and they are more likely to feel troubled in public settings. 
In this study, those patients with primary education status, and having low, above average and high family monthly income were significantly associated with poor QoL which is contrary to a study done in India [33]. Such discrepancy might result from a difference in cultural settings, adjustment of confounding factors, DLQI cut-off point, and analysis model. Patients taking systemic therapy were significantly associated with less affected quality of life which might be owing to its more aggressive, comfortable, and less time-consuming nature as compared to topical therapy. This result is supported by findings from a cohort study in Spain [33].

Our study had some limitations. The temporal relationship between the dependent and independent variables does not be allowed due to cross-sectional nature of the study design. The other limitation is that the drugs considered during analysis were those prescribed at the time of recent follow-up; it didn't include drugs that were switched or withdrawn. This study also considered only pharmacologic interventions due to poor recording practice of the hospital.

\section{Conclusion}

Topical corticosteroids were the most commonly prescribed treatment modality, which accounted for $89.4 \%$, for the treatment of psoriasis. Mean DLQI was 6.25, corresponding to a moderate effect on the quality of life, while symptoms and feelings were the most highly affected domain. Female gender, primary education level, and having low, above average, and high monthly family income were significantly associated with markedly reduced quality of life while receiving systemic therapy significantly associated with a better quality of life. Hence, future interventions targeting improving QoL and widening treatment options for psoriasis deemed to be necessary.

\section{Acknowledgments}

We acknowledge ALERT Center for allowing us to conduct this study. The authors also would like to acknowledge all participants, data collectors, staff working in the dermatologic clinic of ALERT Center for their time, and voluntary facilitation for the data collection process.

\section{Author Contributions}

Conceptualization: Seifu Megersa Kumsa, Tamrat Assefa Tadesse, Minyahil Alebachew Woldu 
Data curation: Seifu Megersa Kumsa

Formal analysis: Seifu Megersa Kumsa

Investigation Seifu Megersa Kumsa, Tamrat Assefa Tadesse, Minyahil Alebachew Woldu

Supervision: Tamrat Assefa Tadesse, Minyahil Alebachew Woldu

Writing - original draft: Seifu Megersa Kumsa

Writing - review \& editing: Tamrat Assefa Tadesse, Minyahil Alebachew Woldu

\section{Abbreviations}

AOR: Adjusted Odds Ratio

ALERT- All Africa Leprosy, Tuberculosis and Rehabilitation Training

DLQI- Dermatology life quality index

QoL- Quality of life

SPSS: Statistical Package for Social Sciences (SPSS)

\section{References}

1. Belinchon I, Rivera R, Blanch C, Comellas M, Lizan L. Adherence, satisfaction and preferences for treatment in patients with psoriasis in the European Union: a systematic review of the literature. Patient Prefer Adherence. 2016; 10: 2357-67..

2. Boehncke W-H, Schon MP. Psoriasis. Seminar. 2015;983-94.

3. Kim WB, Jerome D, Yeung J. Diagnosis and management of psoriasis. Clin Rev. 2017;63:278-85.

4. Huerto C, Rivero E, Rodriguez LAG. Incidence and Risk Factors for Psoriasis in the General Population. Arch Dermatol. 2007;143:1559-65.

5. Lebwohi M. Psoriasis. Ann Intern Med. 2018; 168: ITC49-64.

6. Voorhees AS Van, Feldman SR, Lebwohl MG, Mandelin A, Ritchlin C. The psoriasis and psoriatic arthritis treatment algorithms and management options. National Psoriasis Foundation. 5th edition. 
7. Schadler DC, Ortel B, Mehlis LS. Disease-a-Month Biologics for the primary care physician : Review and treatment of psoriasis. Disease-a-Month. 2018; 0:1-40.

8. World Health Organization. Global report on psoriasis. 2016; Available from: https://apps.who.int/iris/handle/10665/204417. Accessed on May 252019.

9. García-sánchez L, Montiel-jarquín ÁJ, Vázquez-cruz E, May-salazar A. Quality of life in patients with psoriasis.Gac Med Mex. 2017; 153:185-9.

10. Gottlieb AB. Therapeutic options in the treatment of psoriasis and atopic dermatitis. J Am Acedamy Dermatol. 2005;53:S3-16.

11. Fatani MI, Habibullah TH, Alfif AA, Ibrahim II, Althebyani B. Impact of Psoriasis on Quality of Life at Hera General Hospital in Makkah, Saudi Arabia. Clin Med Diagnostics. 2016;6: 7-12.

12. Palijan T, Koi E, Ru K, Dervinja F. The Impact of Psoriasis on the Quality of Life and Psychological Characteristics of Persons Suffering from Psoriasis. Coll Antropol. 2011;35:81-5.

13. Colombo D, Perego R. Quality of Life in Psoriasis. Intechopen. 2013;142-9.

14. Mendoza-sassi RA. Impact on the quality of life of dermatological patients in Southern Brazil. An Bras Dermattol. 2011;86:1113-21.

15. Bhosle MJ, Kulkarni A, Feldman SR, Balkrishnan R. Quality of life in patients with psoriasis. Health Qual Life Outcomes. 2006;7:1-7.

16. Abdulghani M, Sheik a al, Alkhawajah M, Ammoury A, Behrens F, Benchikhi H, et al. Management of Psoriasis in Africa and the Middle East: a Review of Current Opinion, Practice and Opportunities for Improvement. J Int Med Res. 2011;1573-88.

17. Kragballe UMK, Spuls KRP, Nast CEMGA, Antoniou JFC. Definition of treatment goals for moderate to severe psoriasis : a European consensus. Arch Dermatol Res. 2011;1-10.

18. Cardiff University. Dermatology life quality index [Internet]. 1994. Available from: https://www.cardiff.ac.uk/medicine/resources/quality-of-life-questionnaires/dermatologylife-quality-index

19. Menter A, Korman NJ, Elmets CA, Feldman SR, Gelfand JM, Gordon KB, et al. Guidelines of care for the management of psoriasis and psoriatic arthritis. J Am Dermatology. 2009;60:643-59.

20. Alexander Nast, Boehncke W, Mrowietz U, Ockenfels H, Philipp S, Reich K, et al. European 
S3 guidelines on treatment of psoriasis vulgaris. J Ger Soc Dermatol. 2012; 51-95

21. Raboobee N, Group W, Aboobaker J, Jordaan HF, Sinclair W, Smith JM, et al. Guideline on the management of psoriasis in South Africa. S Afr Med J. 2010;100:257-82.

22. National Psoriasis Foundation. The psoriasis and psoriatic arthritis. 2016;5th edition.

23. Papp K, Gulliver W,Lynde C, Poulin Y, Ashkenas J. Canadian Guidelines for the Management of Plaque Psoriasis. J Cutan Med Surg. 2011; 15: 210-9.

24. Vettuparambil A, Neelakandhan A. Psoriasis can markedly impair the quality of life of patients irrespective of severity: Results of a hospital-based cross-sectional study. 2016;7: $111-4$.

25. Saaya NN, Khan I, Affandi AM. Epidemiology and Clinical Features of Adult Patients with Psoriasis in Malaysia : 10-Year Review from the Malaysian Psoriasis Registry (2007 - 2016). Hindawi. 2018; 2018: 1-8.

26. Kubanov AA, Bakulev AL, Fitileva T V., Novoderezhkina E, Gilloteau I, Tian H, et al. isease Burden and Treatment Patterns of Psoriasis in Russia: A Real-World Patient and Dermatologist Survey. Dermatol Ther (Heidelb). 2018; 8:581-92.

27. Eid AA, Elweshahi HM. Quality of life of Egyptian patients with psoriasis : a hospital- based cross-sectional survey. Egypt J Dermatology Venereol. 2016;36:11-7.

28. Barot PA,Brahmbhatt NA, , Malhotra Quality of life in patients with psoriasis at a tertiary care teaching hospital - a cross sectional study. Natl J Med Res. 2015;5:93-7.

29. Lin T, See L, Shen Y, Liang C, Chang H, Lin Y. Quality of Life in Patients with Psoriasis in Northern Taiwan. Chang Gung Med J. 2010;186-96.

30. Nagrani P, Roy S, Jindal R. Quality of life in psoriasis : a clinical study. Int J Res Dermatol. 2019;5:1-6.

31. Rolstad T, Gelfand JM, Feldman SR, S.Stern R, Thomas J, Margolis DJ. Determinants of quality of life in patients with psoriasis: A study from the US population. Am Acad Dermatology. 2004;704-8.

32. Pita-Fernandez S, Torres RMF, Fonseca E. Quality of life and related factors in a cohort of plaque-type psoriasis patients in La Coruna. Int J Dermatol. 2014;53: 507-11.

33. Nayak, Girisha, Noronha. Correlation between Disease Severity, Family Income, and Quality of Life in Psoriasis: A Study from South India. Indian Dermatol Online J. 2018;9:165-9. 


\section{Figure}

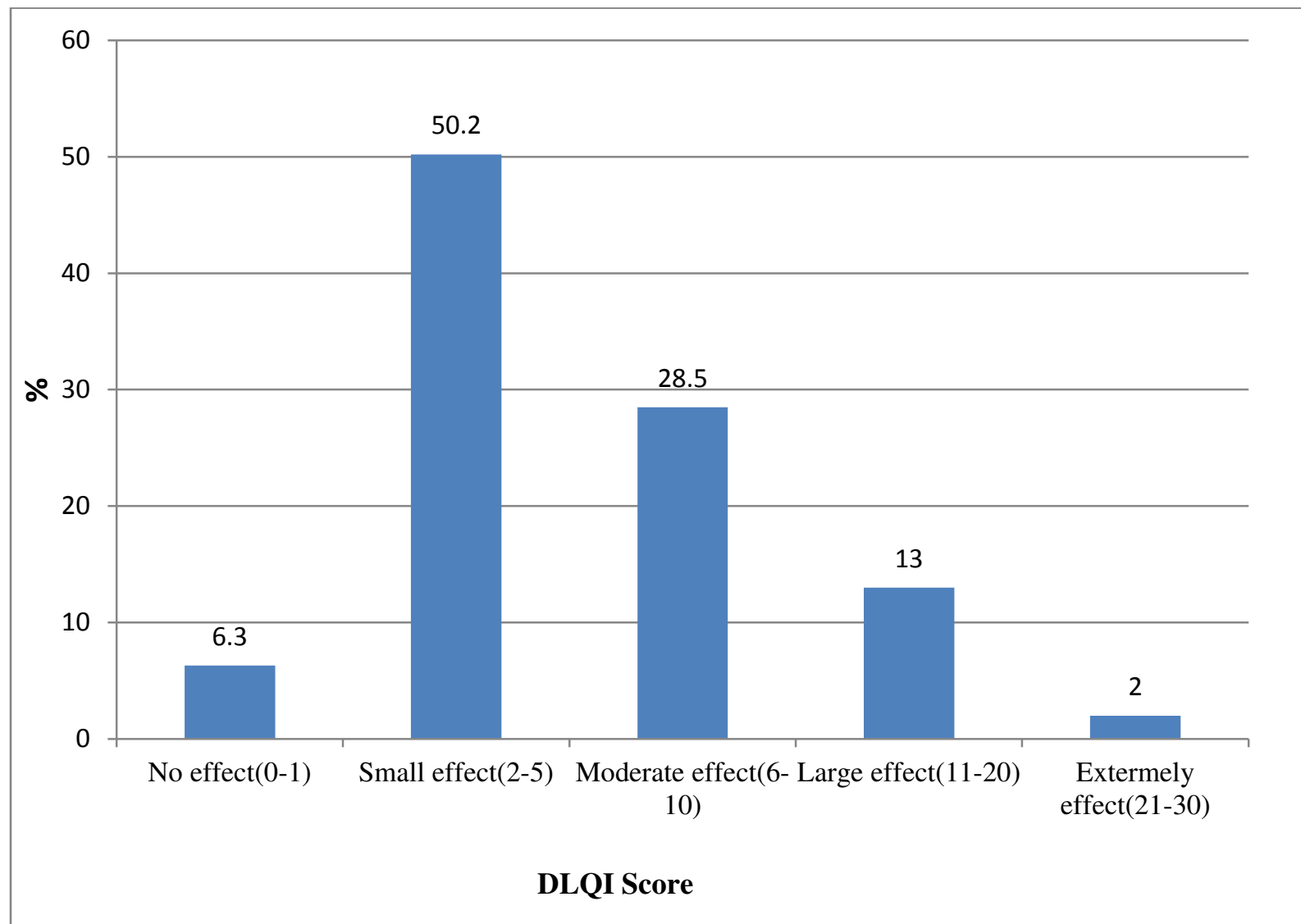


Figures

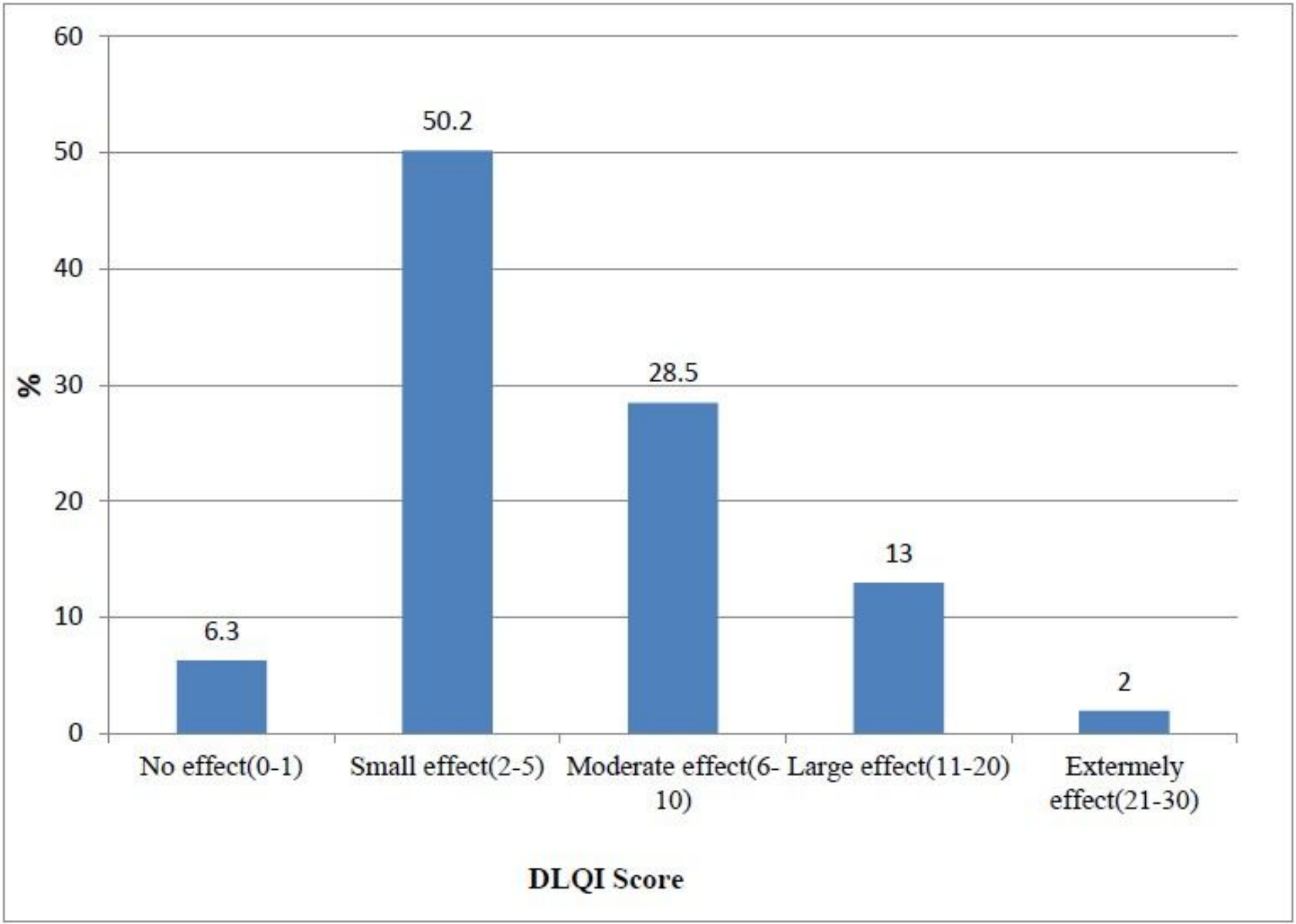

\section{Figure 1}

Proportion of overall effect of psoriatic on quality of life among psoriasis patients attending ALERT Hospital, Addis Ababa, Ethiopia ( $\mathrm{N}=207)$. 